\title{
PARA ALÉM DO OTIMISMO: A SUSTENTABILIDADE NA MODA DURANTE A PANDEMIA
}

\author{
BEYOND OPTIMISM: SUSTAINABILITY IN FASHION DURING THE PANDEMIC
}

\author{
ALINE ZANZI| UDESC \\ ICLEIA SILVEIRA, Dra. | UDESC \\ LUCAS DA ROSA, Dr. | UDESC \\ NEIDE KÖHLER SCHULTE, Dra. | UDESC
}

\begin{abstract}
RESUMO
O objetivo deste artigo é identificar se a pandemia causada pela Covid-19 impactou as ações relacionadas à sustentabilidade que já estavam sendo praticadas na indústria da moda, relacionando desenvolvimento sustentável, moda e consumo. Foi realizada uma pesquisa básica, descritiva e de natureza qualitativa, com coleta de dados realizada por meio de questionário aberto junto à duas empresas de grande porte e que possuem ações relativas à sustentabilidade incorporadas em suas operações, sendo fundamentada por revisão bibliográfica, por meio de consultas em livros e sites, análise de estudos de mercado e de matérias recentes veiculadas na imprensa. Por intermédio das respostas obtidas, pode-se observar que, mesmo em meio aos inúmeros desafios provocados pela pandemia, não houve mudanças ou interrupções no curso das ações com foco em sustentabilidade entre as empresas pesquisadas e, por se tratar de um contexto ainda em construção, o legado da Covid-19 para a moda permanece incerto.
\end{abstract}

PALAVRAS-CHAVE: Covid-19; Sustentabilidade; Moda.

\begin{abstract}
The purpose of this article is to identify whether the COVID-19 pandemic impacted the actions related to sustainability that were already being practiced in the fashion industry, relating sustainable development, fashion and consumption. A basic, descriptive and qualitative research was carried out, with data collection carried out through an open questionnaire, with two large companies that have actions related to sustainability incorporated in their operations, being supported by bibliographic review, through consultations on books and websites, analysis of market studies and recent articles published in the specialized press. Through the responses obtained, it can be observed that even in the midst of the numerous challenges caused by the pandemic, there were no changes or interruptions in the course of actions focused on sustainability among the companies surveyed and, because it is a context still under construction, COVID-19's legacy for fashion remains uncertaina.
\end{abstract}

KEY WORDS: Covid-19; Sustainability; Fashion. 


\section{INTRODUÇÃO}

A pandemia mundial, causada pela Covid-19, acelerou mudanças em diversas áreas e impactou profundamente no modo de vida da sociedade contemporânea. Com as medidas adotadas pelos países na tentativa de conter a disseminação do vírus, o impacto econômico tornou-se inevitável e ocorreu em esfera global. 0 Fundo Monetário Internacional (FMI) estima que o ano de 2020 foi o pior ano para a economia mundial desde a crise de 1929 (GOPINATH, 2020). A indústria da moda está entre as mais afetadas, com números que apresentam uma queda expressiva. No Brasil, o setor entrou para a lista do Ministério da Economia como um dos mais impactados após o decreto de calamidade pública decorrente da pandemia (BRASIL, 2020b).

Segundo os dados publicados pelo Serviço Brasileiro de Apoio às Micro e Pequenas Empresas (Sebrae), a queda no faturamento semanal dos pequenos negócios de moda chegou a $74 \%$ no início da pandemia (SEBRAE, 2020), semelhante ao divulgado pelo Instituto Brasileiro de Geografia e Estatística (IBGE), que revela uma porcentagem de queda equivalente a $75,5 \%$ nas vendas do varejo de tecidos, vestuário e calçados no mês de abril de 2020, o pior resultado para o setor nos últimos vinte anos (CABRAL, 2020). A queda nos números não é apenas fruto dos bloqueios que impactaram diretamente na cadeia de produção, mas, também, conduzida por mudanças nos hábitos de consumo: os itens não essenciais, como itens de vestuário, perderam espaço durante os primeiros meses de confinamento.

Em meio ao caos e às incertezas ocasionadas pela pandemia, e com a necessidade da indústria em gerenciar a crise econômica num curto prazo para subsistir no mercado, será que as medidas e ações guiadas para o desenvolvimento sustentável, que vinham atingindo peso e proporções mais expressivas nos últimos anos, estariam sendo ameaçadas?

As questões envolvendo sustentabilidade estão longe de ser novidade e já estavam em pauta no setor de moda muito antes da Covid-19, sendo, inclusive, um dos seus maiores desafios, levando em conta que a indústria da moda é identificada como uma das grandes responsáveis pelo desequilíbrio ambiental do planeta. Avançando para a transição pós-pandemia e sob uma ótica otimista, há indícios e estudos de comportamento que apontam que os próximos anos serão propícios para uma revisão de práticas, tanto por parte da indústria como dos consumidores.

0 presente artigo busca identificar se a pandemia causada pela Covid-19 impactou nas ações relacionadas à sustentabilidade que já estavam sendo praticadas na indústria da moda, relacionando desenvolvimento sustentável, moda e consumo. 0 estudo se justifica, portanto, pela necessidade de reconhecimento da realidade das práticas da indústria, que visa auxiliar na construção de um prognóstico quanto aos rumos da sustentabilidade na moda.

Classifica-se, portanto, como uma pesquisa de natureza básica, qualitativa e descritiva, com coleta de dados realizada mediante um questionário aberto e aplicado à duas empresas de grande porte, que possuem ações relativas à sustentabilidade incorporadas em suas operações. Fundamenta-se por meio de revisão bibliográfica, consultas em livros e sites, análise de estudos de mercado e matérias recentes veiculadas na imprensa.

\section{PANDEMIA, SUSTENTABILIDADE E MODA}

0 ano de 2020 ficará para sempre marcado como um período desafiador para a sociedade contemporânea. 0 surto de uma nova doença, posteriormente denominada como Covid-19, causada por um vírus até então desconhecido e relatado pela primeira vez em Wuhan, província de Hubei (China), em 31 de dezembro de 2019 (OPAS, 2020b). O coronavírus se espalhou pelo mundo, causando milhares de mortes e trazendo efeitos avassaladores em escala global.

A maneira como a Covid-19 se espalhou rapidamente é fruto de um mundo sem fronteiras, que está totalmente conectado e que permite que uma pessoa possa atravessar o globo em poucos dias. Para se ter uma ideia, antes dos bloqueios, 200 mil aviões cruzavam os céus diariamente. Desde o primeiro relato da doença, em 31 de dezembro de 2019, até o fechamento das fronteiras chinesas, em 21 de janeiro de 2020, mais de 7 milhões de pessoas já haviam deixado a região, o que facilitou a disseminação da doença ao redor do mundo (CAFÉ DA MANHÃ, 2020).

No Brasil, o primeiro caso confirmado pelo Ministério da Saúde foi em 26 de fevereiro de 2020, na cidade de São Paulo. Um homem de 61 anos, com histórico de viagem para a região da Lombardia, na Itália, local que se tornou um dos epicentros da doença fora do território chinês (BRASIL, 2020a). Em 11 de março de 2020, a Organização Mundial de Saúde (OMS) caracterizou o surto como uma epidemia mundial. Segundo a folha informativa divulgada em 23 de outubro de 2020, o número de infectados pelo coronavírus ultrapassou o número 
de 42 milhões de pessoas no mundo, com mais de um milhão de mortes confirmadas pela doença (OPAS, 2020a).

A chegada da Covid-19 deixou o mundo à beira de um colapso. Inúmeras medidas foram tomadas na tentativa de conter a disseminação do vírus, mas a principal delas foi o isolamento social. Vários países adotaram restrições rígidas quanto à circulação de pessoas nos primeiros meses de pandemia, o que incluiu a paralisação de atividades não essenciais, o fechamento de estabelecimentos comerciais e até mesmo o bloqueio de fronteiras. A crise de saúde pública impactou diretamente a economia dos países e o agravamento de problemas sociais, escancarando a interconexão entre o meio ambiente, a economia e a sociedade.

A interdependência entre os sistemas naturais e - sistema socioeconômico é abordada por Krucken (2009) e, segundo a autora, essa relação pode ser reconhecida justamente diante das crises ambientais e dos problemas de ordem global, que vêm se acentuando nas últimas décadas. Uma pandemia, como a causada pelo coronavírus, pode ser incluída como uma das consequências do desequilíbrio entre esses sistemas.

A análise clínica dos primeiros casos de humanos infectados pelo novo coronavírus revelou que os pacientes frequentaram, em dezembro de 2019, o mercado atacadista de frutos do mar e de animais vivos em Wuhan. Ainda existem incertezas em relação às espécies envolvidas como hospedeiras do atual SARS-CoV-2. Peter Ben Embarek, especialista em zoonoses e doenças alimentares da OMS, comunicou que a Covid-19 foi originada em morcegos, dada a semelhança genômica da Sars-Cov-2 com o coronavírus encontrado na espécie, porém, um outro ramo de investigações sobre a origem da Covid-19 também observa a alta semelhança do vírus SARS-CoV-2 com os coronavírus localizados nos pangolins malaios. O pangolim é o animal mamífero mais traficado do mundo nesse século. Essa espécie de mamífero é dotada de escamas e popularmente conhecida pela sua participação ancestral na medicina tradicional asiática, bem como pode ser encontrada nos mercados de animais silvestres chineses (LIMA, 2020; NATIONAL GEOGRAPHIC, 2020).

0 aparecimento de zoonoses incide sobre as inter-relações entre humanos e fauna, já que o surgimento dessas novas doenças é fruto da interferência humana no meio ambiente. DiasLima (2020) lista, ainda, outros elementos que estão associados ao aparecimento de novas pandemias: as viagens ao redor do mundo, a globalização, a urbanização desorganizada, os desmatamentos e a poluição ambiental.

Uma reportagem divulgada pela Universidade Federal de Juiz de Fora (UFJF) relata que a baixa atividade humana dos últimos meses trouxe uma série de consequências e efeitos para a sociedade, porém, no que diz respeito ao meio ambiente, muitos dos impactos foram positivos. Fotos de cidades e lugares turísticos, onde a natureza se regenerou durante as medidas de isolamento social, circularam pelas redes sociais. Uma das mais compartilhadas foi a dos canais de Veneza, que ficaram cristalinos após a primeira semana de quarentena, um estado que não ocorria há 60 anos (UFJF, 2020).

As consequências das ações do homem no meio ambiente, principalmente relacionadas ao desenvolvimento econômico, vêm sendo debatidas desde meados do século XX. Em 1962, o livro Primavera Silenciosa, de Rachel Carson, impulsionou o movimento ambientalista ao abordar o uso de pesticidas químicos no cultivo agrícola e a importância da preservação dos ecossistemas para a vida humana (ONU, 2020). Gwilt (2014) afirma que, entre as décadas de 1960 e 1970, os ambientalistas passaram a levantar preocupações com os danos causados ao meio ambiente, principalmente aos ocasionados pela sociedade capitalista, iniciando a busca por meios mais sustentáveis para a produção e o consumo.

No ano de 1972, a Organização das Nações Unidas (ONU) sediou, em Estocolmo, na Suécia, a Conferência das Nações Unidas sobre o Ambiente Humano. A declaração final do evento culminou em um manifesto ambiental, composto por 19 princípios, que estabeleceu os pilares da nova agenda ambiental adotada pelo sistema das nações unidas. A partir da conferência foi elaborado o Programa das Nações Unidas para o Meio Ambiente, que trata dos aspectos ambientais no que se refere ao meio ambiente em nível global (ONU, 2020).

O conceito de desenvolvimento sustentável foi inserido nas discussões públicas no ano de 1987, durante a Comissão Mundial sobre Meio Ambiente e Desenvolvimento. O relatório da comissão, intitulado "Nosso futuro comum" - também conhecido como Relatório de Brundtland -, conceitua, em um dos seus trechos, o desenvolvimento sustentável como "o desenvolvimento que atende as necessidades atuais, sem comprometer a habilidade das futuras gerações de atender suas próprias necessidades" (ONU, 2020, não paginado).

Para Sachs (2009, p. 58) “o desenvolvimento sustentável é um desafio planetário”. Segundo o 
autor, o termo é, geralmente, relacionado à sustentabilidade ambiental, porém o conceito possui diversas dimensões. Entre estas dimensões, o autor lista a sustentabilidade social como a mais importante, sobretudo por ser a finalidade do próprio desenvolvimento sustentável; a sustentabilidade ambiental, que acontece em decorrência da primeira, e a sustentabilidade econômica, que aparece como uma necessidade, e não uma condição para as anteriores.

No que se refere ao desenvolvimento sustentável, Berlim (2016, p. 17) aponta que esse está fundamentado sob três pilares: "justiça social, viabilidade econômica e preservação ambiental". De acordo com Manzini e Vezzoli (2008), a sustentabilidade deve ser encarada, sobretudo, como um objetivo a ser atingido, e não como uma direção a ser seguida. Isso porque, segundo os autores, nem tudo que propõe melhorias ambientais pode ser visto como algo sustentável.

O atual sistema em que a moda opera, e o próprio modelo econômico no qual a sociedade contemporânea está baseada, contraria os critérios necessários para alcançar a sustentabilidade. Para Hawley (2011), a indústria da moda está essencialmente contrária ao conceito de ambientalismo. Pensamento que é compartilhado por Farrer (2011), ao afirmar que a indústria da moda simboliza a insustentabilidade por meio de suas tendências que mudam rapidamente e com a obsolescência programada de seus produtos.

Fletcher e Grose (2011, p. 8) afirmam que a relação da moda com os sistemas mais amplos, como economia, ecologia e sociedade, é complexa. Segundo as autoras, a sustentabilidade é

“[...] a maior crítica que a indústria da moda já enfrentou, pois desafia a moda em seus detalhes (fibras e processos) e também com relação ao todo (modelos econômicos, metas, regras, sistema de crenças e valores)".

A moda faz parte do cotidiano, da cultura e das relações humanas em sociedade, é um elemento fundamental para a contemporaneidade e pode ser considerada até mesmo indissociável dela, já que a maioria dos seres humanos do planeta estão rodeados por artigos têxteis e cobertos por roupas.

Mais de 102 milhões de toneladas de roupas serão consumidas na próxima década, segundo o sumário executivo divulgado pelo Conselho de Designers de Moda da América (CFDA, 2020). Devido à dimensão de produção e consumo, Berlim (2016) cita a produção de têxteis como uma das atividades mais poluidoras do século, que tem como os seus principais impactos ambientais a contaminação das águas e do ar. Salcedo (2014) contribui quantificando os impactos da indústria e responsabilizando-a por $20 \%$ da contaminação dos recursos hídricos da Terra, assim como por $10 \%$ de toda emissão de gás carbônico $\left(\mathrm{CO}_{2}\right)$ do planeta.

\footnotetext{
Além de demandar muita energia na produção e transporte de seus produtos, a indústria têxtil polui o ar com emissões de gases de efeito estufa; as águas com as químicas usadas nos beneficiamentos, tingimentos e irrigação de plantações; e o solo, com pesticidas de alta toxidade. Além disso os resíduos que permanecem nos produtos podem contaminar quem os usa (BERLIM, 2016, p. 33).
}

Fletcher e Grose (2011) destacam o contraste que existe entre os meios de produção industrial, que envolvem a manufatura e o varejo (como é o caso da moda); em relação à linguagem na qual operam os sistemas naturais, com ciclos, fluxos, redes e interconectividade.

Segundo Mcquillan (2011), o acesso às informações, matérias-primas e aos bens de consumo estão facilitados de tal maneira, na sociedade contemporânea, que muitas vezes os impactos causados ao projetar, fornecer e consumir são ignorados. Para a autora, a combinação da produção barata do vestuário, somada à velocidade das tendências de moda, obrigaram a indústria a atuar de maneira rápida. Porém, é necessário projetar novos sistemas de moda, que atendam ao desejo de flexibilidade e mudança, sem impactar o meio ambiente e a sociedade.

Mesmo antes da crise causada pela Covid-19, a sustentabilidade não era tarefa fácil para muitas empresas de moda. Cietta (2017) afirma que conciliar sustentabilidade e moda é um grande desafio, sendo que a sustentabilidade é um processo que não ocorre de forma gratuita e que exige adaptações por parte das empresas, já que, segundo o autor, em sua fase inicial essa transição tem um custo maior do que os métodos de produção não sustentáveis, algo que, de curto a médio prazo, acaba se tornando uma economia e não um custo para a empresa.

Para Fletcher e Grose (2011, p. 10),

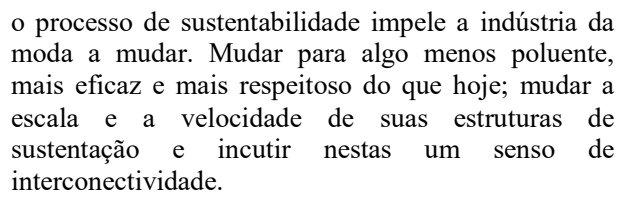

A característica efêmera da moda se associa diretamente à sua insustentabilidade. De fato, essa celeridade faz com que artigos de moda se tornem ultrapassados em um curto espaço de tempo. Pode-se dizer que a efemeridade é um dos principais combustíveis do modelo de 
desenvolvimento econômico capitalista, sendo responsável por estimular o comportamento dos consumidores e por manter os diferentes setores da economia em movimento. Neste contexto, Gwilt (2011) acredita que o real desafio da indústria da moda seja incentivar mudanças de comportamento e não somente projetar e produzir roupas mais sustentáveis observando apenas o ponto de vista ambiental.

Para Kucken (2009), transmitir a qualidade e o conteúdo socioambiental dos produtos e serviços é outro ponto extremamente importante na promoção de soluções sustentáveis. Segundo a autora, a comunicação efetiva com os consumidores pode apoiá-los nos processos de escolha e de apreciação da qualidade.

O CFDA estima que a redução na demanda do consumidor, causada pela pandemia, pode servir como uma chamada de atenção para um movimento mais rápido em direção à sustentabilidade. A instituição analisa a crise atual como uma oportunidade para que a indústria da moda repense a maneira como conduz seus negócios:

\begin{abstract}
A necessidade de esforço coletivo para sobreviver à crise está forçando os participantes da indústria e os consumidores a perceber que suas ações como indivíduos, funcionários de empresas e como cidadãos, têm consequências reais (CFDA, 2020, p. 6 , tradução nossa).
\end{abstract}

O medo e as incertezas geradas pela Covid-19 causaram transformações e mudanças de comportamento, principalmente relacionadas ao consumo de itens não essenciais, como artigos vestuário e moda. Segundo pesquisa realizada pela agência Opinion Box, que investiga 0 impacto nos hábitos de compra e consumo no Brasil desde o início da pandemia, o isolamento social fez com que $49 \%$ dos entrevistados repensassem seu consumo de roupas, calçados e acessórios. 11\% responderam, inclusive, que não pretendiam comprar nada relacionado a roupas e acessórios durante o ano de 2020 (OPINION BOX, 2020).

Houve muita expectativa nos primeiros meses de confinamento de que uma nova mentalidade emergiria do consumidor após a pandemia. Porém, Mathias (2020) afirma que não há indícios de que haverá uma mudança radical nos padrões de acumulação anteriores à pandemia. Para o autor, algumas transformações podem acontecer na margem, assim um "novo normal" surgiria mediante uma transição lenta e gradual, porém estrutural.

Em entrevista recente, Amina Razvi, diretora executiva da Sustainable Apparel Coalition (SAC), fala que a crise gerada pela pandemia trouxe à tona, de maneira mais evidente, alguns dos problemas sistêmicos da indústria, e revelou a fragilidade do sistema. Ela acredita na sustentabilidade como algo urgente, tanto do ponto de vista social quanto ambiental. A diretora afirma, ainda, que as empresas com sustentabilidade integrada de forma holística, em suas operações, estão tendo resultados melhores do que aquelas que isolaram os esforços sustentáveis ou nunca iniciaram a jornada (BROWN, 2020).

Especificamente com relação a vestuário, calçados e têxteis, uma pesquisa desenvolvida pelo Boston Consulting Group (BGC), em parceria com a SAC e com o Higg Co, aponta a tendência $\mathrm{da}$ consolidação da sustentabilidade como expectativa básica em toda a indústria. Os primeiros sinais sugerem que a crise global de saúde aumentará a demanda do consumidor por produtos intimamente associados a confiança, bem-estar e 0 bem coletivo (BOSTON CONSULTING GROUP; THE SUSTAINABLE APPAREL COALITION; HIGG CO, 2020).

A pesquisa desenvolvida por Boston Consulting Group, The Sustainable Apparel Coalition e Higg Co (2020) afirma que, antes da pandemia causada pela Covid-19, a sustentabilidade estava ganhando impulso como um fator importante para consumidores, empresas e investidores. Programas e compromissos ambiciosos que envolviam sustentabilidade estavam se tornando norma nas indústrias de vestuário, calçados e têxteis em segmentos variados, como luxo, esporte, varejo e até mesmo entre as empresas de fast fashion. Porém, ainda segundo a pesquisa, apenas em casos raros uma empresa deve adicionar qualquer novo compromisso de sustentabilidade durante um período de dramática incerteza econômica (BOSTON CONSULTING GROUP; THE SUSTAINABLE APPAREL COALITION; HIGG CO, 2020). Com a finalidade de atender ao objetivo deste artigo, é este perfil empresarial, que possui ações com foco em desenvolvimento sustentável incorporado nas suas operações, que será observado como parte desta pesquisa.

\section{METODOLOGIA}

Quanto ao objetivo de estudo, aplicou-se a pesquisa descritiva, procurando identificar os fatores que contribuem para o fenômeno investigado, aprofundando, assim, o conhecimento da realidade das empresas foco da pesquisa. Quanto ao critério de abordagem, trata-se de uma pesquisa qualitativa, que visa desenvolver modelos, tipologias e teorias para descrever ou explicar as questões sociais (GIL, 2007). Para chegar à resposta do problema de pesquisa foram necessárias algumas etapas 
sistemáticas do método científico, que são descritas a seguir:

1. Pesquisa bibliográfica - adotada durante todo o trabalho, especialmente como subsídio ao desenvolvimento do aporte teórico.

2. Pesquisa de campo - que recolheu informações para responder ao problema de pesquisa. Organizou-se um questionário com questões abertas, que foi enviado por e-mail para os responsáveis pelo setor de sustentabilidade de cada empresa. A amostra da pesquisa contou com duas empresas, uma nacional e outra multinacional, ambas de grande porte, produtoras de artigos de vestuário, identificadas como empresa "A" e empresa "B", mantendo, assim, o sigilo das mesmas.

0 critério de escolha baseou-se não somente no porte e relevância perante a indústria brasileira, mas também no fato de serem companhias que já possuíam a sustentabilidade incorporada aos seus processos, com projetos de redução de impacto já aplicados em sua cadeia de produção, além de contarem um departamento específico para as questões envolvendo a temática.

3) Análise de dados - na qual se fez o tratamento, por inferências e interpretações dos dados coletados. A partir desta etapa realizou-se a interpretação, análise e discussão dos resultados.

Como é possível observar nos resultados a seguir, não foram elaboradas perguntas quanto ao porte, número de vendas e produção, tais informações foram obtidas por meio de relatórios divulgados pelas empresas participantes em seus canais próprios. Além disso, por não se tratar de uma pesquisa quantitativa, as respostas obtidas não foram analisadas e descritas na forma de gráficos ou tabelas quantitativamente, mas sim, de modo descritivo e qualitativo.

\section{RESULTADOS DA PESQUISA DE CAMPO}

A empresa "A" é uma multinacional estrangeira, que soma mais de 1.8 mil unidades, estando presente em diversos países, com aproximadamente 51 mil funcionários em todo o mundo e mais de 1 milhão de trabalhadores de vestuário em sua cadeia de suprimentos. Segundo o relatório de sustentabilidade global do ano de 2019, disponibilizado on-line, a companhia pretende reduzir $30 \%$ de sua pegada de carbono até 2030. Além disso, $94 \%$ de todo algodão utilizado como matéria-prima em seus produtos é de origem orgânica e certificada. A empresa também divulga $100 \%$ de seus fornecedores de nível 1 e 2 , sendo a pioneira no Brasil a se reportar quanto à sustentabilidade, no ano de 2010. De acordo com informações publicadas no site da empresa "A", a mesma estabeleceu diversos compromissos quanto à sustentabilidade ambiental e social, que envolvem a monitoração e certificação de todos os fornecedores da cadeia, a neutralização da emissão de gases responsáveis pelo efeito estufa, a redução no volume de água utilizado nos processos, entre outros.

A empresa "B" é nacional e, segundo dados extraídos a partir do último relatório anual divulgado on-line em abril de 2018 pela empresa, a produção da companhia foi de 11 milhões de peças de vestuário e 2,2 milhões de calçados no ano de 2017, contando com uma força produtiva de 2.387 colaboradores. A receita bruta do grupo no mesmo ano foi de 474.4 milhões, sendo que pouco mais de $1 \%$ desde total foi destinado a investimentos em proteção ambiental. Os objetivos relacionados ao meio ambiente que integram o relatório da empresa " $B$ " envolvem racionalizar o uso de recursos naturais, priorizar fontes de energia mais limpas e minimizar os impactos gerados ao meio ambiente, decorrentes dos processos produtivos. A empresa também afirma que realiza o gerenciamento dos resíduos sólidos e o tratamento de efluentes.

A primeira pergunta do questionário indaga há quanto tempo as ações com foco em sustentabilidade foram adotadas pela empresa e se houve mudança, devido à pandemia, nas ações que já estavam sendo praticadas.

A empresa "A" afirmou que observa as questões envolvendo sustentabilidade desde 2006, ano em que passou a monitorar sua rede de fornecimento. Foi a partir desse momento que a empresa estruturou um departamento interno de sustentabilidade e passou a publicar relatórios, de acordo com a Global Reporting Initiative. Em 2013 a companhia lançou sua primeira estratégia de sustentabilidade e, desde 2015, passou a abordar o assunto de forma global e unificada em todos os países onde atua. A empresa conta com uma plataforma mundial de sustentabilidade, estruturada sob 3 pilares de atuação: produtos sustentáveis, rede de fornecimento sustentável e vidas sustentáveis. A plataforma inclui metas e compromissos alinhados ao negócio e com entrega de resultados prevista ainda para 2020. Segundo a empresa $A$, não houve mudança nas ações envolvendo sustentabilidade em função da pandemia.

A empresa "B" afirmou que a responsabilidade ambiental faz parte do DNA da empresa, e as ações com foco em sustentabilidade relatadas na resposta envolvem o tratamento de $100 \%$ da água utilizada em suas instalações, a reciclagem e o reuso de mais de $90 \%$ dos resíduos derivados dos 
processos produtivos, sendo que os materiais que não são passíveis de reuso ou reciclagem são encaminhados para aterros sanitários sob responsabilidade da empresa. A companhia também incorporou a logística reversa das embalagens de produtos químicos, reutilizando em torno de $60 \%$ das embalagens. Em suas lojas próprias, franquias e multimarcas nas quais comercializa seus produtos, a empresa " $B$ " fornece aos clientes sacolas oxibiodegradáveis, mencionando, ainda, durante a resposta, participar de um projeto em parceria com um ateliê local, que visa a reutilização de resíduos e sobras de malha na confecção de peças exclusivas.

Quando questionadas se a inserção na esfera da sustentabilidade é uma demanda do cliente ou uma adaptação ao mercado global, a empresa " $A$ " respondeu que a adequação da companhia se deu pelo fato de a empresa compreender a relevância e a necessidade de incorporar essas questões para a própria perenidade do negócio. Por sua vez, a empresa "B" afirmou que leva em consideração a sustentabilidade antes mesmo do tema se tornar um critério de mercado. Porém, a empresa acredita que essa questão também é uma demanda do cliente, que está mais consciente em relação ao futuro do planeta e que faz com que as empresas busquem por adequação. Ainda, segundo a empresa “B”, o grande desafio é inovar em relação aos processos mais sustentáveis.

A terceira pergunta abordou a sustentabilidade como um critério de decisão no momento de compra e se as empresas observaram alguma mudança de comportamento do consumidor devido à pandemia em relação à sustentabilidade. A empresa " $A$ " afirmou que, infelizmente, a sustentabilidade ainda não é um critério de decisão de compra para seus clientes. Porém, a empresa diz observar o aumento da valorização destas questões entre seus consumidores. Já a empresa "B" afirmou que a sustentabilidade é um grande fator de decisão de compra e, para a empresa, o consumidor está mais atento, optando por marcas que tenham compromissos com a sustentabilidade, fator que acaba refletindo em vendas. Essa empresa não observou mudança, devido à pandemia, nos hábitos de seus consumidores.

$\mathrm{Na}$ quarta parte das perguntas, as empresas foram questionadas quanto ao impacto da pandemia em relação à sustentabilidade e se as ações que já vinham sendo executadas foram pausadas ou impulsionadas. A empresa " $A$ " não comentou os impactos sofridos no período, apenas afirmou que a companhia seguiu executando suas ações, principalmente porque
2020 foi o ano final da sua plataforma de sustentabilidade. Para a empresa "B", foram muitos os desafios impostos desde o início da pandemia, e esses têm mudado a cada fase. Nesse momento a empresa passa pela fase de retomada da demanda e se depara com a escassez de recursos, tanto de matérias-primas, quanto de recursos humanos. Além disso, outro desafio citado pela empresa é a questão dos preços e custos. A empresa “B” não estima um aumento no poder de compra de seus consumidores, muito pelo contrário, se questiona como equilibrar a questão dos preços e custos, inflados pela escassez de recursos, já que não tem margem para repassar esses efeitos aos preços finais de seus produtos. A empresa, ainda, afirma que procurou minimizar os impactos por meio de escolhas melhores, voltando-se para suas maiores competências e manejando melhor seus recursos na tentativa de manter a competitividade. Mesmo nesse momento de adversidades, a empresa diz que tem conseguido crescer e que, paralelamente, vem dando sequência às ações sustentáveis que já estavam implantadas antes da pandemia, além de tirar do papel muitos novos projetos.

Ao final do questionário foi perguntado como as empresas planejam os próximos anos em relação à sustentabilidade. Sem muitos detalhes, a empresa " $A$ " apenas afirmou que pretende continuar evoluindo nestas questões e que divulgará, em 2021, os próximos passos de sua jornada. Já a empresa "B" afirmou que tem muitos projetos em andamento. Entre eles, e em fase avançada de desenvolvimento, a empresa citou que pretende adotar o processo de desfibramento, método com o qual conseguirá reutilizar sobras de malha $100 \%$ algodão, reutilizando o fio proveniente do desfibramento na confecção de novos tecidos. A empresa destaca, em sua resposta, um recém-lançado projeto, que consiste na oferta de descontos na compra de peças novas mediante a entrega de roupas infantis usadas da marca, em boas condições e que não estejam mais sendo utilizadas. 0 projeto faz parte de uma parceria entre a empresa " $B$ " e a plataforma digital Enjoei, e busca movimentar a economia circular por meio do varejo de segunda mão.

\section{CONSIDERAÇÕES FINAIS}

Com base nas respostas obtidas, pode-se perceber que a sustentabilidade tem sido, de fato, uma preocupação para as grandes indústrias de moda, e pôde-se conhecer algumas das ações que estão sendo executadas na prática. Positivamente, mesmo em meio aos inúmeros desafios ocasionados pela pandemia e que ainda estão sendo impostos às empresas, 
observou-se que não houve mudanças ou interrupções no curso das ações com foco em sustentabilidade e, mesmo não sendo possível afirmar que este aspecto tenha sido evidenciado pela pandemia, fica claro que o assunto tem ganhado cada vez mais força, tanto por pressão do mercado, quanto por uma parte dos consumidores, que são cada vez mais seletivos em relação ao consumo de produtos sustentáveis.

Outro ponto relevante da pesquisa é o fato de as empresas já estarem observando uma mudança de mentalidade emergindo entre seus clientes. Esse tão esperado novo consumidor, mais consciente e que preza pelo bem-estar social e ambiental envolvido nos produtos que consome, não surgiu como fruto imediato do chamado "novo normal", mas vem surgindo lentamente, por meio de um longo processo, muito mais complexo, que envolve questões culturais, sociais, econômicas e que, sem dúvida, precisa do interesse da própria indústria para existir.

Não se pode negar que a indústria da moda tem evoluído em relação à sustentabilidade, especialmente quando falamos das grandes marcas que possuem maior visibilidade, porém, para a grande maioria da indústria, essa questão ainda está longe de ser uma realidade. A moda precisa passar por um processo de reformulação em todo seu sistema de operação, sendo que, incorporar a sustentabilidade de forma holística é algo fundamental neste processo, e que provoca mudanças estruturais em toda a cadeia.

0 ano de 2020 certamente trouxe ensinamentos e apontou direcionamentos para o futuro da indústria em relação ao uso dos recursos naturais, materiais e do valor do capital humano que compõe as empresas. Porém, por se tratar de um processo ainda em curso, somente a longo prazo, quando finalmente chegarmos ao outro lado da pandemia, é que poderemos conhecer o legado que a COVID-19 deixará para a moda.

\section{REFERÊNCIAS}

BERLIM, Lilyan. Moda e sustentabilidade: uma reflexão necessária. São Paulo: Estação das Letras e Cores, 2016.

BRASIL. Brasil confirma primeiro caso do novo coronavírus. Governo do Brasil, 26 fev. 2020a. Disponível em: https://www.gov.br/pt$\mathrm{br} /$ noticias/saude-e-vigilancia-

sanitaria/2020/02/brasil-confirma-primeiro-casodo-novo-coronavirus. Acesso em: 24 out. 2020.

BRASIL. Ministério da Economia. Gabinete da Secretaria Especial de Produtividade, Emprego e
Competitividade. Portaria $n^{\circ}$. 20.809, de 15 de setembro de 2020. Lista os setores da economia mais impactados pela pandemia após a decretação da calamidade pública decorrente do Covid-19. Diário Oficial da União, Brasília, DF, 15 set. 2020b. p. 47. Disponível em: https: / /www.in.gov.br/web/dou/-/portaria-n20.809-de-14-de-setembro-de-2020-277430324. Acesso em: 15 nov. 2020.

BROWN, Sacha. Rebuilding a more sustainable fashion industry after COVID-19. CFDA, 27 maio. 2020. Disponível em: https://cfda.com/news/rebuilding-a-moresustainable-fashion-industry-after-covid-19. Acesso em: 14 nov. 2020.

BOSTON CONSULTING GROUP; THE SUSTAINABLE APPAREL COALITION; HIGG CO. Rebuilding a More Sustainable Fashion Industry After COVID19. 30 abr. 2020. Disponível em: https: / / apparelcoalition.org/wpcontent/uploads/2020/04/Weaving-a-BetterFuture-Covid-19-BCG-SAC-Higg-Co-Report.pdf. Acesso em: 25 out. 2020.

CABRAL, Umberlândia. Vendas no varejo caem $16,8 \%$ em abril, pior resultado em 20 anos. Agência IBGE Notícias. 16 jun. 2020. Disponível em:

https://agenciadenoticias.ibge.gov.br/agencianoticias/2012-agencia-de-

noticias/noticias/27963-vendas-no-varejo-caem16-8-em-abril-pior-resultado-em-20-anos. Acesso em: 24 out. 2020.

CAFÉ DA MANHA: a segunda onda do coronavírus. Entrevistada: Giuliana Miranda. Entrevistadores: Maurício Meireles, Bruno Bogocian. [S. I.] Folha de São Paulo \& Spotify Studios, 16 out. 2020. Podcast. Disponível em: https://link.tospotify.com/QQjdSUYfrbb. Acesso em: 15 nov. 2020.

CIETTA, Enrico. A economia da moda. São Paulo; Estação das Letras e Cores, 2017.

COUNCIL OF FASHION DESIGNERS OF AMERICA; BOSTON CONSULTING GROUP. Sustainability by design - Rethinking New York Fashion Week. Executive Summary, 2020. Disponível em: https://s3.amazonaws.com/cfda.f.mrhenry.be/2 020/10/Executive-SummaryFINAL-10.7.20.pdf. Acesso em: 25 out. 2020.

DIAS-LIMA, Artur. 0 mundo e o vírus. In: MARQUES, Juracy; DIAS-LIMA, Artur. (org.). Ecologia humana \& pandemias: consequências da COVID-19 para o nosso futuro. Paulo Afonso, BA: SABEH, 2020.

FARRER, Joan. Discussing Fashion Textiles Sustainability. In: GWILT, Alison; RISSANEN, Timo. (Eds.). Shaping sustainable fashion: 
changing the way we make and use clothes. Londres: Earthscan, 2011. p. 19-34.

FLETCHER, Kate; GROSE, Lynda. (org.). Moda \& Sustentabilidade, Design para mudança. São Paulo: Editora Senac, 2011.

GIL, Antônio Carlos. Como elaborar projetos de pesquisa. 4. Ed. São Paulo: Atlas, 2007.

GWILT, Alison. Producing Sustainable Fashion: the points for positive intervention by the fashion designer. In: GWILT, Alison; RISSANEN, Timo. (Eds.). Shaping sustainable fashion: changing the way we make and use clothes. Londres: Earthscan, 2011. p. 59-74.

GWILT, Alison. Moda sustentável: Um guia prático. São Paulo: Gustavo Gili, 2014.

GOPINATH, Gita. The great lockdown: worst economic downturn since the great depression. IMFblog, $14 \mathrm{abr}$. 2020. Disponível em: https://blogs.imf.org/2020/04/14/thegreat-lockdown-worst-economic-downturn-sincethe-great-depression/. Acesso em: 8 nov. 2020.

HAWLEY, M. Jana. Textile recycling options: exploring what could be. In: GWILT, Alison; RISSANEN, Timo. (Eds.). Shaping sustainable fashion: changing the way we make and use clothes. Londres: Earthscan, 2011. p. 143-156.

LIMA, Ramos Rodrigo. A Covid-19 e a relação entre humanos e animais: zoonoses e zooterapias. FIOCRUZ, 2 jul. 2020. Disponível em: http://coc.fiocruz.br/index.php/pt/todasas-noticias/1816-especial-covid-19-a-covid-19-ea-relacao-entre-humanos-e-animais-zoonoses-ezooterapias.html\#.X9U7LNhKjIV. Acesso: $12 \mathrm{dez}$. 2020.

KRUCKEN, Lia. Design e território: valorização de identidades e produtos locais. São Paulo: Studio Nobel, 2009.

MANZINI, Ezio; VEZZOLI, Carlo. 0 desenvolvimento de produtos sustentáveis. Tradução: Astrid de Carvalho. 1. ed. São Paulo: Editora da Universidade de São Paulo, 2008.

MATHIAS, João Felippe Cury M. O que desejamos? Princípios para uma transição socioambiental sustentável pós-pandemia. In: YOUNG, Carlos Eduardo F; MATHIAS, João Felippe Cury M. (orgs.) Covid-19, meio ambiente e políticas públicas 1. Ed. São Paulo: Hucitec, 2020. p. 175-183.

MCQUILLAN, Holly. Zero waste design practice: strategies and risk taking for garment design. In: GWILT, Alison; RISSANEN, Timo. (Eds.). Shaping sustainable fashion: changing the way we make and use clothes. Londres: Earthscan, 2011. p. 83-97.
NAÇÕES UNIDAS BRASIL (ONU). A ONU e o meio ambiente. Disponível em: https://brasil.un.org/pt-br/91223-onu-e-o-meioambiente. Acesso em: 25 out. 2020.

NATIONAL GEOGRAPHIC. Pangolins. [S. I.] 2020. Disponivel em: https: / / www.nationalgeographic.com/animals/ mammals/group/pangolins/. Acesso em: $12 \mathrm{dez}$. 2020.

OPAS BRASIL. Folha informativa COVID-19 Escritório da OPAS e da OMS no Brasil. OPAS BRASIL, 13. nov. 2020a. Disponível em: https://www.paho.org/pt/covid19\#: :text=Fora m\%20confirmados\%20no\%20mundo\%2041.570,23\% 20de\%20outubro\%20de\%202020. Acesso em: 24 out. 2020.

OPAS BRASIL. OMS afirma que COVID-19 é agora caracterizada como pandemia. OPAS Brasil, 11 mar. 2020b. Disponivel em: https: / / www.paho.org/bra/index.php?option=co m_content\&view=article\&id=6120:oms-afirmaque-covid-19-e-agora-caracterizada-comopandemia\&ltemid=812. Acesso em: 24 out. 2020.

OPINION BOX. Impacto nos hábitos de compra e consumo. 2020. Disponível em: https: / /rdstation-

static.s3.amazonaws.com/cms\%2Ffiles $\% 2 F 7540 \% 2$ F1591127455Pesquisa_COVID_19_-_10_EDIO.pdf. Acesso em: 3 out. 2020.

SACHS, Ignacy. Caminhos para o desenvolvimento sustentável. Rio de Janeiro: Garamond, 2009.

SALCEDO, Elena. Moda Ética para um Futuro Sustentável. São Paulo: Editora Gustavo Gili, 2014.

SERVIÇO BRASILEIRO DE APOIO ÀS MICRO E PEQUENAS EMPRESAS (SEBRAE). Pesquisa com empresários: impactos da covid-19 nos pequenos negócios. 2020. Disponível em: https://bibliotecas.sebrae.com.br/chronus/ARQ UIVOS_CHRONUS/bds/bds.nsf/26395e8d6cdfaad1 9dd180ac3d994b80/\$File/19406.pdf. Acesso em: 8 nov. 2020.

UNIVERSIDADE FEDERAL DE JUIZ DE FORA (UFJF). Pandemia e meio ambiente: Impactos momentâneos ou nova normalidade? UFJF Notícias, 24 abr. 2020. Disponível em: https://www2.ufjf.br/noticias/2020/04/24/pand emia-e-meio-ambiente-impactos-momentaneosou-nova-normalidade/. Acesso em: 24 out. 2020. 


\section{AUTORES}

ORCID: https://orcid.org/0000-0003-2681-4849 ALINE ZANZI (AZ)| Universidade do Estado de Santa Catarina - UDESC | Mestrado Profissional em Design de Vestuário e Moda, Florianópolis, SC - Brasil । Correspondência para: Avenida Nereu Ramos, 1051 - Centro, Sombrio - SC, 88960-000। E-mail: aline.zanzi@edu.udesc.br

ORCID: https://orcid.org/0000-0003-4493-9768 ICLEIA SILVEIRA (IS), Dra. I Universidade do Estado de Santa Catarina - UDESC I Mestrado Profissional em Design de Vestuário e Moda Florianópolis, SC - Brasil | Correspondência para: Condomínio Horizontal Costa Leste, 357 - Barra da Lagoa, Florianópolis - SC, 88601-312 | Email: icleiasilveira@gmail.com

ORCID: https://orcid.org/0000-0002-8429-2754

LUCAS DA ROSA (LR), Dr.| Universidade do Estado de Santa Catarina - UDESC I Mestrado Profissional em Design de Vestuário e Moda, Florianópolis, SC - Brasil | Correspondência para: Florianópolis - SC, 88.035-901 | e-mail: darosa.lucas@gmail.com

ORCID: https://orcid.org/0000-0001-5690-5819 NEIDE KÖHLER SCHULTE (NKS), Dra. I Universidade do Estado de Santa Catarina UDESC | Mestrado Profissional em Design de Vestuário e Moda, Florianópolis, SC - Brasil I Correspondência para: Av. Madre Benvenuta, 1907 - Bairro Itacorubi, Florianópolis - SC, 88.035-901 | E-mail: neideschulte@gmail.com

\section{HOW TO CITE THIS ARTICLE}

ZANZI, Aline; SILVEIRA, Icleia; ROSA, Lucas da; SCHULTE, Neide Köhler. Para além do Otimismo: A Sustentabilidade na Moda durante a Pandemia. MIX Sustentável, v. 8, n. 1, p. 19-28, jan. 2022. ISSN-e: 24473073.Disponível em: <http://www.nexos.ufsc.br/index.php/mixsuste ntavel>. DOI: http://dx.doi.org/10.29183/24473073.MIX2022.v8.n1.19-28.

Submitted: 22/03/2021

Approved: 11/08/2021

Published: 01/12/2021

Editor Responsável: Lisiane Ilha Librelotto

Registro da contribuição de autoria:

Taxonomia CRediT (http://credit.niso.org/)

AZ; IS; LR; NKS: validação, escrita -revisão e edição.

AZ; IS; LR: análise formal, administração do projeto.

AZ; NKS: conceituação.

IS; LR: metodologia, supervisão.

IS; AZ: visualização.

AZ: curadoria de dados, investigação, escrita rascunho original.

Declaração de conflito: nada foi declarado. 